\title{
Numeracy
}

\author{
Paul Malik MD FRCPC
}

$\mathrm{T}$ here exists a universal language that transcends the spoken word - it is the language of mathematics. For those gifted in understanding its intricacies, the universe is a beautiful harmony of symmetries. Indeed, the elegance of mathematical precision stands in stark contrast to the brutish approximations of biological disciplines. Neuroscientists have debated whether humans possess an innate understanding of numbers. However, like most other skills, if not cultivated and maintained, it languishes.

The domain of mathematics is not reserved exclusively for advanced degree programs in engineering and physics. It is a necessary quotidian skill. Every individual needs to perform a variety of mathematical functions - basic calculations, estimation, time analyses, probability-based decision making and prediction. Arguably, such basic skills are weaker than previous generations', given our reliance on a plethora of technological aids, starting with the calculator. Such numerical literacy was dubbed 'numeracy' by Sir Geoffery Crowther in 1959 and is distinct from conventional literacy, which deals more with language comprehension and expression. Unfortunately, numeracy has been the deuteragonist to literacy. There is no social stigma attached to innumeracy as there is to illiteracy, and I would speculate that there are many more individuals in the developed world who are innumerate than who are illiterate.

The importance of patient numeracy in the delivery of highquality health care has been recognized. The titration of medications, understanding probability information and the self-management of chronic conditions, including drug dose adjustments and analyzing trends, are all essential skills. However, the level of sophistication among patients in using these skills is highly varied. The first step is to assess patients' levels of numeracy. Traditionally, this has been done using the Test of Functional Health Literacy in Adults (TOFHLA) (1). The TOFHLA consists of 50 reading comprehension items and 17 numerical ability items. It takes up to $22 \mathrm{~min}$ to administer, which considerably limits its routine clinical use. A short form (s-TOFHLA), which takes only $7 \mathrm{~min}$ to administer, is also available, but tests only reading comprehension. To date, administering the s-TOFHLA has not been proven to alter clinical outcomes (2-5). The reasons for this are varied. It may be that numeracy is more important than reading comprehension for improving outcomes. Indeed, low numeracy has been linked to hospitalization for asthma (4). Alternatively, the TOFHLA, and especially the short form, may simply be too all-encompassing to be useful. Rather, a disease-specific instrument may perform better. Finally, tests to determine numerical health literacy must be followed up by therapeutic interventions tailored to the appropriate level. For example, an individual with low numeracy may benefit from more assistance from his or her spouse. Presumably, such individuals would also require more frequent follow-up, because they would be least suitable for selfmanagement strategies.

Although literacy and numeracy are linked, the two do not always go hand in hand. How best to treat literate but poorly numerate individuals is a matter for further study. In the meantime, recognizing the importance of patient numeracy may well improve physician-patient communication. Using words such as 'likely' instead of 'highly probable', for example, may suffice. Furthermore, identifying poorly numerate individuals through only cursory brief interactions is not always reliable. However, as a starting point, the task of formal assessments should be incorporated by the large number of nationwide multidisciplinary chronic disease clinics. This is not as onerous as it sounds. It may start with using only the numerical components of the original TOFHLA or a locally derived, disease-specific set of questions to be answered by patients while in the waiting room. Empowering patients to manage their chronic illnesses long after their time in the specialty clinic is complete involves not only a one-size-fitsall educational strategy, but rather one tailored to their overall health literacy.

\section{Selected sites}

\section{Wikipedia}

<en.wikipedia.org/wiki/numeracy>

2. Montori VM, Rothman RL. Weakness in numbers the challenge of numeracy in health care. J Gen Intern Med 2005;20:1071-2. Also available at <www.pubmedcentral.nih.gov/ articlerender.fcgi?artid=1490258>

\section{REFERENCES}

1. Parker RM, Baker DW, Williams MV, Nurss JR. The test of functional health literacy in adults: A new instrument for measuring patients' literacy skills. J Gen Intern Med 1995;10:537-41.

2. Morris NS, MacLean CD, Littenberg B. Literacy and health outcomes: A cross-sectional study in 1002 adults with diabetes. BMC Fam Pract 2006;7:49.

3. Fang MC, Machtinger EL, Wang F, Schillinger D. Health literacy and anticoagulation-related outcomes among patients taking warfarin. J Gen Intern Med 2006;21:841-6.

4. Apter AJ, Cheng J, Small D, et al. Asthma numeracy skill and health literacy. J Asthma 2006;43:705-10.

5. Seligman H, Wang F, Palacios J, Wilson CD, Piette J, Schillinger D. Physician notification of their diabetes patients' limited health literacy. A randomized, controlled trial. J Gen Intern Med 2005;20:1001-7. Also available at <www.pubmedcentral.nih.gov/ articlerender.fcgi?artid $=1490250>$ 